\title{
Technology Transfer in a Stackelberg Structure: Licensing Contracts and Welfare
}

\author{
By \\ Tarun Kabiraj* \\ Indian Statistical Institute, Kolkata
}

First Draft May 2001

Revised Draft January 2002

*I would like to thank Diganta Mukherjee for a very helpful discussion. The usual disclaimer applies.

Correspondence to: Tarun Kabiraj, Economic Research Unit, Indian Statistical Institute, 203 B. T. Road, Kolkata - 700108.

E-mail: tarunkabiraj@hotmail.com; Fax: 91335778893 


\begin{abstract}
This paper studies the question of optimal licensing contract in a leadership structure when the patent holder of a superior technology is itself a competitor in the product market. The size of the innovation is assumed to be exogenous. It is then shown that which firm (whether leader or follower) owns the patent and what contracts are available to the inventor, have different implications to the consumers and producers separately and as a whole. We examine whose innovation is socially more valuable. Given private incentives of innovation, an appropriate licensing policy can induce the desired firm to win the patent race.
\end{abstract}

Key words: Leadership structure, fee licensing, royalty licensing, innovation, welfare.

JEL classifications: D45, L13. 


\section{Introduction}

Transfer of superior technology is a topic of growing interest. It has many facets. Our particular interest in this paper is to examine the contractual aspect of the problem and to study its welfare implication to different groups like consumers, producers and society as a whole. This, however, crucially depends on the nature of product market. All the works so far contributed in the literature assume a market structure either a monopoly, a competitive market, or a simultaneous-move oligopoly. Surprisingly, the question of technology transfer in a leadership structure and its welfare implication is left unaddressed. This paper is a modest attempt to fill up this gap. To be precise, we assume an initial Stackelberg structure when one firm, either leader, or follower, owns a patent of a cost-reducing technology. We study the question of optimal licensing contract from the perspective of the consumers and producers separately and as a whole. Our prime focus is to examine whose innovation, whether leader's or follower's, is more valuable to the society. We then analyze the licensing policy that should induce the desired firm to win the patent race.

Technology transfer literature considers both fee licensing and royalty licensing. Which contract is appropriate from the perspective of the innovator depends on a number of factors like: what market structure prevails, whether the inventing firm is also the producing firm, whether imitation of a new technology is easy, whether patent protection is perfect, and also, whether the government of the country allows both fee licensing and royalty licensing, or whether it puts restriction on the amount of fee and/or royalty, etc. Quite naturally, the question of patent protection has implication to the imitative capability of firms. Constrained by these factors, technology licensing can be either a fee licensing or a royalty licensing alone, or a mix of the both. In the survey of firms Rostoker (1984) finds that 39\% cases have royalty alone, 13\% cases have fee alone, and the remaining cases have fee plus royalty. To the study of the technology licensing agreements between Indian and foreign firms it is observed that lower royalty rates are associated with higher lump sum payments (see Alam (1985), for instance).

Theoretical works on the question of optimal licensing contract can be traced in many writings, such as Kamien and Tauman (1986), Rockett (1990), Muto (1993) and Wang (1998). An excellent survey on this issue can be found in Kamien (1992). In the first two papers the patent holder is a non-producer which licenses its technology to the oligopoly firms, and the last two papers assume that patent holder is at the same time a competitor in the same product market. Muto (1993) has Bertrand competition with differentiated products and the other papers consider quantity competition in homogeneous goods. Licensing to a perfectly competitive industry by means of both a fee and a royalty is studied in Kamien and Tauman (1984) while Arrow (1962) studies licensing to a perfectly competitive industry and to a monopoly using royalty only. Rockett (1990) has an interesting feature in that it allows firms to choose the age of the technology to be licensed along with the structure of payment. ${ }^{1}$ Evidently, no work so far has addressed to the question of optimal licensing contract in a leadership structure when innovator is also an insider in the industry.

\footnotetext{
${ }^{1}$ See Kabiraj and Marjit $(1992,1993)$ for the possibility of obsolete technology transfer.
} 
Generally it is assumed that either imitation of a new technology is not at all possible or patent protection is perfect so that imitation cannot take place. In such a situation the innovator or patent holder, who is also a competitor in the same product market, has option to use either fee licensing or royalty licensing (or both). In the absence of this assumption, however, it is difficult to write a royalty contract even when the patentee is a non-producer. The reason is that if the invention is imitated, it is difficult to write a contract enforcing the licensee to pay royalties over the period of the agreement. What will happen is that the imitator will imitate the technology once it is transferred and thereafter it will stop payments of royalties. In such a situation the licensor is restricted to a fixed fee licensing only (Katz and Shapiro (1985) and Shapiro (1985)).

This conjecture is consistent with the empirical observations in the licensing contracts between Indian and foreign firms. ${ }^{2}$ In the pre-liberalization period entry of a foreign firm in Indian market was possible only through a technology licensing agreement with a local partner. In such a situation when a foreign firm is to transfer its superior technology to a local monopoly, it extracts the surplus by means of a fixed fee. When some restrictions are put on the lump sum payment, the foreign firm uses both fee plus royalty (per unit) contract; and when further restrictions are put on royalty payments, foreign firms are observed to transfer old generation technologies. Singh (1992) has provided a simple but elegant analytical framework that captures these empirical findings. There are parametric situations when transfer to a domestic duopoly involves both fee and royalty payments. ${ }^{3}$

When patentee is a non-producer, generally fee licensing dominates royalty licensing under Cournot competition because per unit royalty increases marginal cost of production of the competitors, and hence there is a loss of surplus due to inefficiency in production. Consumers also gain under fee contract by getting lower product price. Naturally, its dual result holds in the case of price competition, that is, royalty contract generates larger rents to the patentee (Kamien and Tauman (1986) and Muto (1993)).

As noted earlier, Wang (1998) and Rockett (1990) consider technology licensing in Cournot duopoly when the patent holder is also a competitor in the same product market. ${ }^{4}$ Wang shows that (when both contracts are available) the patent holder strictly prefers royalty licensing to fee licensing if innovation is non-drastic. The reason is that under royalty contract the patentee has a cost advantage over the licensee while both firms compete on equal footing under fee contract. However, consumers are to gain more under fee contract. Similar results follow in Rockett (1990) if either imitation is not possible or it is too costly. Given that the paper takes the quality of the transferred technology as a

\footnotetext{
${ }^{2}$ See a host of articles in the Economic and Political Weekly, Special Number (1985).

${ }^{3}$ Singh (1992) also provides analysis on the payment structure when either the local firm's technological capability or the quality of the foreign technology is unknown to one party.

${ }^{4}$ Marjit (1990) and Katz and Shapiro (1985) also study technology licensing in Cournot duopoly, but they assume fee licensing only. They show that technology licensing will occur between firms which are close in respect of their technological capability. Implicitly, therefore, they assume that transferred technologies can be imitated without a cost by the transferee.
} 
choice variable, the best technology is transferred under this situation. On the other hand, when imitation is less costly, in the optimal contract both fee and royalty may reappear (and there are situations when the first generation technology is not transferred. As imitation becomes easier, more weight is placed on the fixed fee rather than on the royalty.

As we have already noted, one objective of the present paper is to study the optimal licensing contract in a Stackelberg structure. Since firms have asymmetry of moves, therefore which firm owns the patent has is an important bearing to the welfare implication of different groups. This question never arises in the context of any other papers discussed. So our main concern in the paper is to examine whose innovation is more valuable to the consumers and producers, separately and as a whole. We also examine which firm has larger incentives to win and hold the patent of a cost-reducing technology. This is extended to analyze whether the government by its licensing policy can induce the desired firm to win the patent race.

So far the optimal licensing contract is concerned from the perspective of the innovator, our result is closely related to Wang (1998). However, there are important differences as well. Like Wang, in our paper royalty licensing dominates fee licensing, but when leader is the innovator, this happens if and only if the size of the innovation is below a critical level, whereas if follower is the innovator, royalty is preferred to fee licensing for all nondrastic innovations. ${ }^{5}$

In our analysis, which firm innovates and which contract is available to the innovator are quite interesting from the viewpoint of welfare of different groups. This is certainly missing in other papers. We show that when both contracts are available to the innovator, follower's innovation is more valuable to the firms in the aggregate, while leader's innovation is considered more valuable from the perspective of consumers' and social welfare. In contrast, if only fee contract is available (this is the case when patent protection is imperfect and imitation of a superior technology is easy), industry profits are larger if leader is the innovator. There are parametric situations when follower's innovation is considered more valuable to consumers as well as to the society. ${ }^{6}$

In our paper the size of the innovation is exogenous. This determines the welfare of different groups via its effect on the choice of the licensing contract. We have shown that if the licensing contract can be manipulated by means of government policy, then no matter which firm innovates, social welfare is larger under fee contract if the innovation is quite small, and royalty contract is socially preferred if the innovation size is relatively larger. For all intermediate cases fee licensing generates a larger welfare if follower is the innovator and royalty licensing yields a larger welfare if leader is the innovator.

This leads to the question of which contract is to be chosen as a matter policy by the government. First we have shown that follower has the larger incentive to innovate if

\footnotetext{
${ }^{5}$ Both in simultaneous move game and sequential move game if innovation is drastic, no transfer occurs.

${ }^{6} \mathrm{We}$ shall later see that it is always the same whether only royalty contract is available or both royalty and fee contracts are available.
} 
both royalty and fee contracts are allowed whereas leader has more incentives if fee contract alone is allowed. Then conditional on the size of the innovation, the optimal policy should be to allow both royalty and fee licensing if the innovation size belongs to some intermediate interval, but the policy should be allowing fee licensing alone if it is either small or large.

The paper is organized as follows. The second section examines which licensing contract, whether fee licensing or royalty licensing, is optimal from the viewpoint of the innovator. We provide welfare analysis in the third section. This examines which licensing contract gives larger welfare to consumers and producers, separately and as a whole. In this section we also study which firm's innovation is socially more valuable. In the fourth section we have discussed innovative incentives of each of leader and follower under different possible contracts. The fifth section suggests the optimal licensing policy in this context. Finally, the concluding section summarizes the results of the paper.

\section{Model: Licensing in a Stackelberg Structure}

We consider a Stackelberg structure with two firms; firm 1 is leader and firm 2 follower. The market demand function for a homogeneous product is assumed to be linear. This is, in inverse form, given by the equation

$$
P=a-Q=a-\left(q_{1}+q_{2}\right)
$$

where $P$ is the price of the product and $q_{i}$ is the supply of the $\mathrm{i}$-th firm, $i=1,2$. Initially, firms are identical and each firm produces at a constant unit cost of production $c, 0<c<a$. We assume that only one firm is capable of inventing a cost-reducing innovation, and the innovation size is exogenous. Also there is no uncertainty, all firms are risk neutral. Then the innovating firm comes up with a patent of a cost-reducing innovation that reduces its unit cost by the amount $\varepsilon$. So the patent holder's unit cost becomes $c-\varepsilon$ and the other firm's cost remains at $c$.

Then we study the possibility of technology licensing from the innovating firm to the other. The licensing game is the following. The patent holder offers either a fixed fee licensing contract or a royalty-licensing contract. The non-patent holder decides whether to accept the contract. We assume that it will accept if it receives at least its reservation payoff. Then firm 1 acts as a first-mover in setting its quantity. Finally, firm 2 decides its quantity production, taking firm 1's quantity as fixed. When the patent holder gives the licensing contract, it wants to maximize its total payoff which is the sum of the profits accrued from its market operation and the licensing revenue in the form of either fixed fee or royalty. ${ }^{7}$

\footnotetext{
${ }^{7}$ Analysis and the results of this section are closely related to Wang (1998). Wang has a Cournot structure while we have a Stackelberg structure. There are also subtle differences of the results between these two models.
} 


\subsection{Stackelberg Structure}

If $c_{1}$ and $c_{2}$ be the constant unit cost of production by firm 1 and 2 respectively, then given the market demand by equation (1), the Stackelberg equilibrium quantities will be

$$
q_{1}\left(c_{1}, c_{2}\right)=\frac{a-2 c_{1}+c_{2}}{2} \text { and } q_{2}\left(c_{1}, c_{2}\right)=\frac{a-3 c_{2}+2 c_{1}}{4}
$$

and the corresponding payoffs will be

$$
\pi_{1}\left(c_{1}, c_{2}\right)=\frac{\left(a-2 c_{1}+c_{2}\right)^{2}}{8} \text { and } \pi_{2}\left(c_{1}, c_{2}\right)=\frac{\left(a-3 c_{2}+2 c_{1}\right)^{2}}{16} \text {. }
$$

With the assumption of $c_{1}=c_{2}=c$, the initial quantities and payoffs are:

$$
q_{1}^{0}=\frac{a-c}{2}, q_{2}^{0}=\frac{a-c}{4}, \pi_{1}^{0}=\frac{(a-c)^{2}}{8}, \pi_{2}^{0}=\frac{(a-c)^{2}}{16} .
$$

From the expressions of (2) we can observe that when $c_{1} \neq c_{2}$, it is possible that in equilibrium the high cost firm produces zero output. Thus when $c_{1}<c_{2}$,

$$
q_{2}=0 \quad \text { if } \varepsilon=c_{2}-c_{1} \geq \frac{a-c_{2}}{2}
$$

Similarly, when $c_{2}<c_{1}$,

$$
q_{1}=0 \quad \text { if } \varepsilon=c_{1}-c_{2} \geq a-c_{1}
$$

Before we go to the next subsection let us recall the concepts of 'drastic' and 'nondrastic' innovations. Let $P_{m}\left(c_{i}\right)$ denote the (unrestricted) monopoly price for the marginal cost $c_{i}$. Then $c_{i}$ is drastic relative to $c_{j}\left(>c_{i}\right)$ if $P_{m}\left(c_{i}\right) \leq c_{j}$. Thus a firm possessing a major or drastic innovation emerges as pure monopoly. In our model, initially both firms have marginal costs equal to $c$. Then one firm, either leader or follower comes up with a reduction of marginal cost of the amount $\varepsilon$. Then $\varepsilon$ may be called the size of the innovation. Hence, with the demand function (1), the innovation is drastic if $\varepsilon \geq a-c$; it is non-drastic if $\varepsilon<a-c$. On observing (5) and (6) we can note an interesting feature of the leadership structure. When $\varepsilon \geq a-c$, the innovator necessarily becomes a pure monopoly, and therefore, it produces a monopoly output, $q_{m}=(a-c+\varepsilon) / 2$, and the other firm has zero output. But when leader is the innovator, follower's optimum output becomes zero even before the innovation becomes drastic. This is clear from (5) that $q_{2}=0$ for $\varepsilon \geq(a-c) / 2$. However, firm 1 acts as restricted (i.e., limit pricing) monopoly for $(a-c) / 2 \leq \varepsilon<a-c$, and thus producers $q_{1}=a-c$. Below we shall consider the possibility of a licensing contract in each of the following cases, viz., the case when leader holds the patent of the new technology, and the case when follower holds it. 


\subsection{Licensing contracts when leader is the innovator}

Assume that firm 1 holds the new technology, $c-\varepsilon$, and firm 2 has old technology, $c$. Then given $\varepsilon$, we can derive equilibrium quantities under no licensing situation as follows:

$$
\begin{aligned}
& q_{1}^{N}=\frac{a-c+2 \varepsilon}{2} \quad \text { and } \quad q_{2}^{N}=\frac{a-c-2 \varepsilon}{4} \quad \text { if } \varepsilon<(a-c) / 2 \\
& =a-c \quad=0 \quad \text { if }(a-c) / 2 \leq \varepsilon<a-c \\
& =\frac{a-c+\varepsilon}{2} \quad=0 \quad \text { if } \varepsilon \geq a-c
\end{aligned}
$$

The corresponding profits under no licensing situation are given by,

$$
\begin{aligned}
& \pi_{1}^{N}=\frac{(a-c+2 \varepsilon)^{2}}{8} \text { and } \pi_{2}^{N}=\frac{(a-c-2 \varepsilon)^{2}}{16} \text { if } \varepsilon<(a-c) / 2 \\
& =\varepsilon(a-c) \quad=0 \quad \text { if }(a-c) / 2 \leq a-c \\
& =\frac{(a-c+\varepsilon)^{2}}{4} \quad=0 \quad \text { if } \varepsilon \geq a-c
\end{aligned}
$$

Note that firm 1 acts as a pure monopoly only when $\varepsilon \geq a-c$. It behaves as a limitpricing monopolist when $(\mathrm{a}-\mathrm{c}) / 2 \leq \varepsilon<a-c$.

\subsubsection{Fixed fee licensing contract}

Under fixed-fee licensing contract the patent holder (here firm 1) will transfer its superior technology to firm 2 and in turn will charge a fee $F>0$ to extract as much surplus as possible from the licensee. The post-transfer quantities and payoffs as originated from market operation are

$$
\begin{aligned}
& q_{1}^{F}=\frac{a-c+\varepsilon}{2} \text { and } q_{2}^{F}=\frac{a-c+\varepsilon}{4}, \\
& \pi_{1}^{F}=\frac{(a-c+\varepsilon)^{2}}{8} \text { and } \pi_{2}^{F}=\frac{(a-c+\varepsilon)^{2}}{16} .
\end{aligned}
$$

Since firm 2's reservation payoff is $\pi_{2}^{N}$, as is given in (8), which is its payoff under no transfer situation, the corresponding fee of technology transfer is

$$
\begin{aligned}
\mathrm{F}=\pi_{2}^{F}-\pi_{2}^{N} & =\frac{(a-c+\varepsilon)^{2}}{16}-\frac{(a-c-2 \varepsilon)^{2}}{16} & & \text { if } \varepsilon<(a-c) / 2 \\
& =\frac{(a-c+\varepsilon)^{2}}{16}-0 & & \text { if } \varepsilon \geq(a-c) / 2
\end{aligned}
$$

This gives a total payoff to the licensor from licensing its technology under fixed fee contract as 


$$
\begin{array}{rlrl}
\Pi_{1}^{F}=\mathrm{F}+\pi_{1}^{F} & =\frac{3(a-c+\varepsilon)^{2}}{16}-\frac{(a-c-2 \varepsilon)^{2}}{16} & & \text { if } \varepsilon<(a-c) / 2 \\
& =\frac{3(a-c+\varepsilon)^{2}}{16} & \text { if } \varepsilon \geq(a-c) / 2
\end{array}
$$

Then, a fee-licensing contract is profitable if and only if the post-transfer total payoff of the licensor is greater than its payoff under no license situation, that is, $\Pi_{1}^{F}>\pi_{1}^{N}$. We can check that

$$
\begin{aligned}
& \Pi_{1}^{F}>\pi_{1}^{N} \Leftrightarrow \varepsilon<\frac{2(a-c)}{9} \\
& \Pi_{1}^{F} \leq \pi_{1}^{N} \quad \text { otherwise }
\end{aligned}
$$

Hence we have the following lemma.

Lemma 1: When leader is the innovator, fee licensing is profitable if and only if the innovation size is quite small (i.e., $\varepsilon<2(a-c) / 9)$.

\subsubsection{Royalty licensing contract}

Under royalty contract, given that the leader firm holds the patent, the innovator transfers its technology and fixes a royalty $r$ per unit of the licensee's output so that the latter's unit cost of production becomes $c-\varepsilon+\mathrm{r}, 0 \leq \mathrm{r} \leq \varepsilon$, while licensor's unit cost remains to be $c-\varepsilon$. With this, their output and profit expressions are

$$
\begin{gathered}
q_{1}^{R}=\frac{a-c+\varepsilon+r}{2} \text { and } q_{2}^{R}=\frac{a-c+\varepsilon-3 r}{4} \\
\pi_{1}^{R}=\frac{(a-c+\varepsilon+r)^{2}}{8} \text { and } \pi_{2}^{R}=\frac{(a-c+\varepsilon-3 r)^{2}}{16} .
\end{gathered}
$$

Thus, $q_{2}^{R} \geq 0$ iff $r \leq \frac{a-c+\varepsilon}{3}$. Then licensor's problem in this case is:

$$
\max _{r} \pi_{1}^{R}+r q_{2}^{R} \quad \text { s.t. } \quad r \leq \varepsilon \text { and } r \leq \frac{a-c+\varepsilon}{3}
$$

The solution to the unconstrained optimization problem is

$$
\hat{r}=\frac{2(a-c+\varepsilon)}{5}>\frac{a-c+\varepsilon}{3} .
$$

Also

$$
\hat{r} \leq \varepsilon \Rightarrow \varepsilon \geq \frac{2(a-c)}{3} \text { and } \varepsilon \leq(\text { or, }>) \frac{\mathrm{a}-\mathrm{c}+\varepsilon}{3} \Leftrightarrow \varepsilon \leq(\text { or },>) \frac{a-c}{2} \text {. }
$$

Hence the optimal solution to the problem stated in (16) is

$$
\begin{aligned}
r^{*}=\varepsilon & \text { if } \quad \varepsilon<\frac{a-c}{2} \\
=\frac{a-c+\varepsilon}{3} & \text { if } \varepsilon \geq \frac{a-c}{2}
\end{aligned}
$$


Given the equilibrium royalty rates (19), the equilibrium quantities are obtained from (14),

$$
\begin{aligned}
& q_{1}^{R}=\frac{a-c+2 \varepsilon}{2} \text { and } q_{2}^{R}=\frac{a-c-2 \varepsilon}{4} \quad \text { if } \varepsilon<\frac{a-c}{2} \\
& =\frac{2(a-c+\varepsilon)}{3} \quad=0 \quad \text { if } \varepsilon \geq \frac{a-c}{2}
\end{aligned}
$$

Then payoffs from market operation are obtained from (15),

$$
\begin{aligned}
& \pi_{1}^{R}=\frac{(a-c+2 \varepsilon)^{2}}{8} \text { and } \pi_{2}^{R}=\frac{(a-c-2 \varepsilon)^{2}}{16} \text { if } \varepsilon<\frac{a-c}{2} \\
& =\frac{2(a-c+\varepsilon)^{2}}{9} \quad=0 \quad \text { if } \varepsilon \geq \frac{a-c}{2}
\end{aligned}
$$

Hence firm 1's total payoff under royalty contract is,

$$
\begin{aligned}
\Pi_{1}^{R}=\pi_{1}^{R}+r q_{2}^{R} & =\frac{(a-c+2 \varepsilon)^{2}}{8}+\varepsilon \frac{(a-c-2 \varepsilon)}{4} & \text { if } \varepsilon<\frac{a-c}{2} \\
& =\frac{2(a-c+\varepsilon)^{2}}{9} & \text { if } \varepsilon \geq \frac{a-c}{2}
\end{aligned}
$$

Comparing $\Pi_{1}^{R}$ and $\pi_{1}^{N}$ we have,

$$
\begin{aligned}
& \Pi_{1}^{R}>\pi_{1}^{N} \text { if } \varepsilon<\frac{a-c}{2} \\
& \Pi_{1}^{R} \leq \pi_{1}^{N} \text { if } \varepsilon \geq \frac{a-c}{2}
\end{aligned}
$$

Hence we have the following result.

Lemma 2: When leader holds the patent of the new technology, a royalty licensing strictly dominates no licensing if and only if the innovation is not large (i.e., $\varepsilon<(a-c) / 2$ ).

\subsubsection{Fee licensing vs. royalty licensing}

We can now decide the optimal licensing strategy of the leader-cum-innovator. It will choose the contract that yields the largest profit, given the size of the innovation. Comparing (13) and (24), if $\varepsilon \geq(a-c) / 2$, no licensing is strictly preferred to each of fee licensing and royalty licensing. When $2(a-c) / 9 \leq \varepsilon<(a-c) / 2$, no licensing dominates fee licensing but royalty licensing dominates no licensing. Finally, if $\varepsilon<2(a-c) / 9$, each of fee licensing and royalty licensing is preferred to no licensing, but in this case, comparing firm 1's payoffs under these two contracts we can see that

$$
\Pi_{1}^{R}>\Pi_{1}^{F}
$$

This gives the following proposition. 
Proposition 1: Assume that leader holds the patent of an innovation of size $\varepsilon$. Then,

(a) When both fee licensing and royalty licensing are available, royalty licensing will be the optimal choice if and only if $\varepsilon<(a-c) / 2$; otherwise, no licensing will be the preferred option.

(b) When only fee licensing is available, licensing will occur if and only if the innovation size is sufficiently small (i.e., $\varepsilon<2(a-c) / 9)$.

\subsection{Licensing contracts when follower is the innovator}

Consider the case when follower holds the patent of the new technology $c-\varepsilon$, whereas leader has its old technology $c$. Then in the no technology transfer situation both firms will operate at positive output level if the innovation is non-drastic (i.e., if $\varepsilon<a-c$ ), but leader will emerge as pure monopoly if the innovation is drastic (i.e., if $\varepsilon \geq a-c$ ). Therefore, the equilibrium quantities under no transfer situation are

$$
\begin{aligned}
& \widetilde{q}_{1}^{N}=\frac{a-c-\varepsilon}{2} \text { and } \widetilde{q}_{2}^{N}=\frac{a-c+3 \varepsilon}{4} \quad \text { if } \varepsilon<a-c \\
& =0 \quad=\frac{a-c+\varepsilon}{2} \quad \text { if } \varepsilon \geq a-c
\end{aligned}
$$

The corresponding payoffs will be

$$
\begin{array}{rlrl}
\tilde{\pi}_{1}^{N} & =\frac{(a-c-\varepsilon)^{2}}{8} \text { and } \tilde{\pi}_{2}^{N}=\frac{(a-c+3 \varepsilon)^{2}}{16} & \text { if } \varepsilon<a-c \\
& =0 & & \text { if } \varepsilon \geq a-c
\end{array}
$$

In the following two subsections we discuss briefly the possibility of fee licensing and royalty licensing, respectively.

\subsubsection{Fixed fee licensing contract}

Here follower holds the superior technology. If now technology transfer occurs from follower to leader, the equilibrium quantities and payoffs will be

$$
\begin{aligned}
& \tilde{q}_{1}^{F}=\frac{a-c+\varepsilon}{2} \text { and } \tilde{q}_{2}^{F}=\frac{a-c+\varepsilon}{4}, \\
& \tilde{\pi}_{1}^{F}=\frac{(a-c+\varepsilon)^{2}}{8} \text { and } \tilde{\pi}_{2}^{F}=\frac{(a-c+\varepsilon)^{2}}{16} .
\end{aligned}
$$

Note that the quantity and profit expressions in (27) and (28) are exactly the same as that in (9) and (10), that is, post-transfer equilibrium quantities and payoffs of the firms are the same independent of the question of who holds the patent of the new innovation. Since firm 1's reservation payoff is its no transfer payoff, $\tilde{\pi}_{1}^{N}$, the optimal fee under licensing will be 


$$
\begin{aligned}
\widetilde{\mathrm{F}}=\tilde{\pi}_{1}^{F}-\tilde{\pi}_{1}^{N} & =\frac{(a-c+\varepsilon)^{2}}{8}-\frac{(a-c-\varepsilon)^{2}}{8} & & \text { if } \varepsilon<a-c \\
& =\frac{(a-c+\varepsilon)^{2}}{8} & & \text { if } \varepsilon \geq a-c
\end{aligned}
$$

Therefore, the total payoff of firm 2 under fee licensing contract is

$$
\begin{aligned}
\widetilde{\Pi}_{2}^{F}=\widetilde{\mathrm{F}}+\tilde{\pi}_{2}^{F} & =\frac{3(a-c+\varepsilon)^{2}}{16}-\frac{(a-c-\varepsilon)^{2}}{8} & & \text { if } \varepsilon<a-c \\
& =\frac{3(a-c+\varepsilon)^{2}}{16} & & \text { if } \varepsilon \geq a-c
\end{aligned}
$$

Comparing $\widetilde{\Pi}_{2}^{F}$ and $\tilde{\pi}_{2}^{N}$ we can see that

$$
\begin{aligned}
& \widetilde{\Pi}_{2}^{F}>\tilde{\pi}_{2}^{N} \text { if } \quad \varepsilon<\frac{a-c}{2} \\
& \widetilde{\Pi}_{2}^{F} \leq \tilde{\pi}_{2}^{N} \text { if } \quad \varepsilon \geq \frac{a-c}{2}
\end{aligned}
$$

Hence, we have the following lemma.

Lemma 3: If follower is the innovator, fee licensing is strictly preferred to no licensing if and only if the size of the innovation is not very large (i.e., $\varepsilon<(a-c) / 2$ ).

\subsubsection{Royalty licensing contract}

Let $r$ be the royalty per unit of firm 1's output as charged by firm 2 for transferring its superior technology to firm 1 under royalty contract. With this, their output and profit expressions, as originated from market operation, are,

$$
\begin{aligned}
& \widetilde{q}_{1}^{R}=\frac{a-c+\varepsilon-2 r}{2} \text { and } \widetilde{q}_{2}^{R}=\frac{a-c+\varepsilon+2 r}{4} \\
& \tilde{\pi}_{1}^{R}=\frac{(a-c+\varepsilon-2 r)^{2}}{8} \text { and } \tilde{\pi}_{2}^{R}=\frac{(a-c+\varepsilon+2 r)^{2}}{16}
\end{aligned}
$$

Thus, $\widetilde{q}_{1}^{R} \geq 0$ iff $r \leq \frac{a-c+\varepsilon}{2}$. Hence the problem of the licensor here is

$$
\max _{r} \tilde{\pi}_{2}^{R}+r \widetilde{q}_{1}^{R} \quad \text { s.t. } \quad r \leq \varepsilon \text { and } r \leq \frac{a-c+\varepsilon}{2}
$$

Free maximization of the above problem yields

$$
\bar{r} \equiv \frac{a-c+\varepsilon}{2} \text {. }
$$

Then

$$
\bar{r} \leq \varepsilon \Leftrightarrow \varepsilon \geq a-c .
$$

Therefore, the optimal royalty in this case is 


$$
\begin{aligned}
\widetilde{r} & =\varepsilon \quad \text { if } \quad \varepsilon<a-c \\
& =\bar{r} \text { if } \quad \varepsilon \geq a-c
\end{aligned}
$$

Thus when the innovation is drastic, firm 1's optimal output choice is zero and firm 2 emerges as pure monopoly. Therefore, under royalty licensing the equilibrium quantities are obtained as follows.

$$
\begin{array}{rlrl}
\widetilde{q}_{1}^{R} & =\frac{a-c-\varepsilon}{2} \text { and } \widetilde{q}_{1}^{R}=\frac{a-c+3 \varepsilon}{4} \quad \text { if } \varepsilon<a-c \\
& =0 & & =\frac{a-c+\varepsilon}{2} \text { if } \varepsilon \geq a-c
\end{array}
$$

Thus outputs under royalty contract are exactly the same as that under no transfer case. This generates,

$$
\begin{aligned}
\pi_{1}^{R} & =\frac{(a-c-\varepsilon)^{2}}{8} \text { and } \pi_{1}^{R} & =\frac{(a-c+3 \varepsilon)^{2}}{16} & \text { if } \varepsilon<a-c \\
& =0 & & \text { if } \varepsilon \geq a-c
\end{aligned}
$$

Under this situation, firm 2's total payoff under royalty contract is

$$
\begin{aligned}
\widetilde{\Pi}_{2}^{R}=\tilde{\pi}_{2}^{R}+r \widetilde{q}_{1}^{R} & =\frac{(a-c+3 \varepsilon)^{2}}{16}+\varepsilon \frac{(a-c-\varepsilon)}{2} & & \text { if } \varepsilon<a-c \\
& =\frac{(a-c+\varepsilon)^{2}}{4} & & \text { if } \varepsilon \geq a-c
\end{aligned}
$$

It is easy to see that

$$
\begin{array}{ll}
\widetilde{\Pi}_{2}^{R}>\widetilde{\pi}_{2}^{N} & \text { if } \varepsilon<a-c \\
\widetilde{\Pi}_{2}^{R}=\widetilde{\pi}_{2}^{N} & \text { if } \varepsilon \geq a-c
\end{array}
$$

Hence, we can write the following lemma.

Lemma 4: When follower is the innovator, royalty contract is strictly profitable compared to no licensing if and only if the innovation is non-drastic (i.e., $\varepsilon<a-c$ ).

\subsubsection{Fee licensing vs. royalty licensing}

Comparing (31) and (41) we see that when follower holds the patent of a drastic innovation, from the perspective of the licensor no licensing dominates both fee licensing and royalty licensing. When the innovation is non-drastic and $(a-c) / 2 \leq \varepsilon<a-c$, royalty licensing is the only chosen option compared to no licensing, as fee licensing is not feasible in this case. When $\varepsilon<(a-c) / 2$, both fee licensing and royalty licensing are feasible, but we have

$$
\widetilde{\Pi}_{2}^{R}>\widetilde{\Pi}_{2}^{F}
$$

Hence we have the following proposition. 
Proposition 2: Assume that follower is the innovator of an innovation of size $\varepsilon$. Then,

(a) When both fee licensing and royalty licensing are available, royalty licensing is the optimal strategy to the transferor if the innovation is non-drastic; otherwise, no licensing is the outcome.

(b) When only fee licensing is available, licensing will occur if and only of the innovation size is not large enough (i.e., $\varepsilon<(a-c) / 2$ ).

Results underlying Propositions 1 and 2 may be explained as follows. When both contracts are available, royalty contract dominates fee contract from the perspective of the patent holder, because under royalty contract the transferor can retain its competitive advantage in the post-transfer situation, whereas under fee contract it is to compete with the transferee on equal footing. Further, the critical level at which technology transfer becomes profitable is less when leader is the innovator compared to the case when follower is the innovator. The reason is the following. In leadership structure, because of the move advantage leader has a relatively larger profit in the pre-transfer situation and hence it cannot afford a larger innovation to make the transfer profitable.

\section{Welfare analysis}

In this section we provide a welfare analysis from the viewpoint of consumers and producers and both. In particular, we examine whose innovation is more valuable to different groups separately as well as to the society as a whole. We also study which contract generates larger welfare to the respective groups. Consumers' welfare will be measured by consumers' surplus (CS), and producers' welfare by industry profit $(\Pi)$. Given the form of the demand function in our paper, $C S=(Q)^{2} / 2$. Hence the overall welfare will be estimated by taking the sum of consumers' surplus and industry profit, that is,

$$
W=C S+\Pi \text {. }
$$

As we shall see, the respective welfare of different groups depends on three factors, viz., the size of the innovation, the nature of the licensing contract allowed and the type of innovator, that is, whether leader or follower.

\subsection{Technology transfer not allowed}

First consider the case when technology transfer is not allowed. Now, if firm 1 is the innovator, from (7) industry output is derived as follows.

$$
\begin{aligned}
Q_{N}=q_{1}^{N}+q_{2}^{N} & =\frac{3(a-c)+2 \varepsilon}{4} & & \text { if } \varepsilon<\frac{a-c}{2} \\
& =(a-c) & & \text { if } \frac{a-c}{2} \leq \varepsilon<a-c \\
& =\frac{a-c+\varepsilon}{2} & & \text { if } \varepsilon \geq a-c
\end{aligned}
$$

The corresponding industry profit derived from (8) is

$$
\Pi_{\mathrm{N}}=\pi_{1}^{N}+\pi_{2}^{N}=\frac{1}{16}\left[3(a-c)^{2}+12 \varepsilon^{2}+4 \varepsilon(a-c)\right] \text { if } \varepsilon<\frac{a-c}{2}
$$




$$
\begin{array}{ll}
=\varepsilon(a-c) & \text { if } \frac{a-c}{2} \leq \varepsilon<a-c \\
=\frac{(a-c+\varepsilon)^{2}}{4} & \text { if } \varepsilon \geq a-c
\end{array}
$$

Similarly, when firm 2 is the innovator, from (25) industry output is

$$
\begin{aligned}
\widetilde{Q}_{N}=\widetilde{q}_{1}^{N}+\widetilde{q}_{2}^{N} & =\frac{3(a-c)+\varepsilon}{4} & & \text { if } \varepsilon<a-c \\
& =\frac{a-c+\varepsilon}{2} & & \text { if } \varepsilon \geq a-c
\end{aligned}
$$

and the corresponding industry profit derived from (26) is

$$
\begin{aligned}
\widetilde{\Pi}_{\mathrm{N}}=\tilde{\pi}_{1}^{N}+\tilde{\pi}_{2}^{N} & =\frac{1}{16}\left[3(a-c)^{2}+11 \varepsilon^{2}+2 \varepsilon(a-c)\right] & \text { if } \varepsilon<a-c \\
& =\frac{(a-c+\varepsilon)^{2}}{4} & \text { if } \varepsilon \geq a-c
\end{aligned}
$$

Comparing (44) and (46), and (45) and (47) we have,

$$
\begin{aligned}
& Q_{N}>\widetilde{Q}_{N} \text { and } \Pi_{N}>\widetilde{\Pi}_{N} \text { if } \varepsilon<a-c \\
& Q_{N}=\widetilde{Q}_{N} \text { and } \Pi_{N}=\widetilde{\Pi}_{N} \text { if } \varepsilon \geq a-c
\end{aligned}
$$

Quite obviously, if the innovation is non-drastic, under no transfer situation overall welfare is larger when leader innovates compared to when follower innovates, that is,

$$
\begin{aligned}
& W_{N}>\widetilde{W}_{N} \quad \text { if } \varepsilon<a-c \\
& W_{N}=\widetilde{W}_{N} \text { if } \varepsilon \geq a-c
\end{aligned}
$$

This gives the following proposition.

Proposition 3: If technology transfer is not allowed, then in a Stackelberg leadership structure, leader's innovation is more valuable than that of the follower to both consumers and producers, separately and as a whole.

\subsection{Technology licensing allowed}

Now assume that technology transfer is allowed. Hence firms will make a licensing contract when it is privately profitable. However, whether technology licensing will occur or not depends on the nature of the licensing contract and on the size of the innovation. It also depends on who the innovator is. For example, if the innovation is drastic, technology licensing will never occur whoever innovates. In the following analysis we denote by $Q_{i}$ and $\Pi_{i}$ the equilibrium industry output and profit, respectively, when firm $i$ is the innovator $(i=1,2)$.

\subsubsection{Welfare when both licensing contracts are available}

Assume that firms are capable of writing any of fixed fee and royalty contracts. From the analysis of subsections 2.2 .3 and 2.3 .3 we know that royalty contract strictly dominates 
fee contract (whenever contracts are feasible). Hence, it does make no difference whether both fee contract and royalty contract are available, or only royalty contract is available.

First consider that leader (firm 1) is the innovator. From Proposition 1 we know that equilibrium outcome is royalty licensing if $\varepsilon<(a-c) / 2$; otherwise the outcome is no licensing. Therefore, in equilibrium the industry output will be

$$
\begin{aligned}
Q_{1} & =Q_{R}=q_{1}^{R}+q_{2}^{R}=\frac{3(a-c)+2 \varepsilon}{4} & & \text { if } \varepsilon<\frac{\mathrm{a}-\mathrm{c}}{2} \\
& =Q_{N}=q_{1}^{N}+q_{2}^{N}=a-c & & \text { if } \frac{\mathrm{a}-\mathrm{c}}{2} \leq \varepsilon<a-c \\
& =Q_{N}=q_{1}^{N}+q_{2}^{N}=\frac{a-c+\varepsilon}{2} & & \text { if } \varepsilon \geq a-c
\end{aligned}
$$

and industry profit

$$
\begin{aligned}
\Pi_{1} & =\Pi_{R}=\Pi_{1}^{R}+\pi_{2}^{R}=\frac{1}{16}\left[3(\mathrm{a}-\mathrm{c})^{2}+4 \varepsilon^{2}+8 \varepsilon(\mathrm{a}-\mathrm{c})\right] & & \text { if } \varepsilon<\frac{\mathrm{a}-\mathrm{c}}{2} \\
& =\Pi_{N}=\pi_{1}^{N}+\pi_{2}^{N}=\varepsilon(a-c) & & \text { if } \frac{\mathrm{a}-\mathrm{c}}{2} \leq \varepsilon<a-c \\
& =\Pi_{N}=\pi_{1}^{N}+\pi_{2}^{N}=\frac{(a-c+\varepsilon)^{2}}{4} & & \text { if } \varepsilon \geq a-c
\end{aligned}
$$

When firm 2 is the innovator, from Proposition 2, equilibrium is royalty licensing if $\varepsilon<a-c$; otherwise, no licensing is the outcome. Hence, industry output obtained in this situation is:

$$
\begin{aligned}
Q_{2} & =\widetilde{Q}_{R}=\widetilde{q}_{1}^{R}+\widetilde{q}_{2}^{R}=\frac{3(a-c)+\varepsilon}{4} \quad \text { if } \varepsilon<\mathrm{a}-\mathrm{c} \\
& =\widetilde{Q}_{N}=\widetilde{q}_{1}^{N}+\widetilde{q}_{2}^{N}=\frac{a-c+\varepsilon}{2} \quad \text { if } \varepsilon \geq \mathrm{a}-\mathrm{c}
\end{aligned}
$$

The corresponding industry profit (derived from (39), (40) and (26)) is

$$
\begin{aligned}
\Pi_{2} & =\widetilde{\Pi}_{R}=\widetilde{\Pi}_{2}^{R}+\tilde{\pi}_{1}^{R}=\frac{1}{16}\left[3(\mathrm{a}-\mathrm{c})^{2}+3 \varepsilon^{2}+10 \varepsilon(\mathrm{a}-\mathrm{c})\right] & & \text { if } \varepsilon<\mathrm{a}-\mathrm{c} \\
& =\widetilde{\Pi}_{N}=\tilde{\pi}_{2}^{N}+\tilde{\pi}_{1}^{N}=\frac{(a-c+\varepsilon)^{2}}{4} & & \text { if } \varepsilon \geq \mathrm{a}-\mathrm{c}
\end{aligned}
$$

We can then check that,

$$
\begin{aligned}
& Q_{1}>Q_{2} \text { and } \Pi_{1}<\Pi_{2} \text { if } \varepsilon<a-c \\
& Q_{1}=Q_{2} \text { and } \Pi_{1}=\Pi_{2} \text { if } \varepsilon \geq a-c
\end{aligned}
$$

Thus, whenever the innovation is non-drastic, the interests of the consumers and producers are diametrically opposing as to who should be the innovator. Let us denoting by $W_{i}$ the overall welfare when firm $i$ is the innovator, $(i=1,2)$. Then we have,

$$
W_{1}>W_{2} \text { if } \varepsilon<a-c \text {, and } W_{1}=W_{2} \text { if } \varepsilon \geq a-c
$$


Proposition 4: When both royalty contract and fee contract are available, while follower's innovation is more valuable to the producers, consumers' welfare as well as the social welfare are (weekly) larger if leader holds the patent of the innovation.

\subsubsection{Welfare when only fee contract is available}

In this section we assume that the innovator has an option to write a fee contract when it is profitable. From Propositions 1(b) and 2(b) we know that if firm 1 is the innovator, technology licensing will occur if and only if $\varepsilon<2(a-c) / 9$. When firm 2 is the innovator, it will license its technology if and only if $\varepsilon<(a-c) / 2$; in all other cases no transfer will be the equilibrium outcome. Then depending on the size of the innovation we have different scenarios. (i) If $0<\varepsilon<2(a-c) / 9$, fee licensing will occur irrespective of which firm innovates; (ii) if $2(a-c) / 9 \leq \varepsilon<(a-c) / 2$, technology transfer will occur only if firm 2 innovates; (iii) if $(a-c) / 2 \leq \varepsilon<a-c$, there will be no transfer of technology, but if firm 1 is the innovator, it will act as a limit pricing monopolist; (iv) finally, if $\varepsilon \geq a-c$, again there will be no technology transfer, but the innovator will emerge as pure monopoly. We examine whose innovation is more valuable to consumers and producers, separately and as a whole. The equilibrium outputs and profits are given below:

$$
\begin{aligned}
& Q_{1}=Q_{F}=\frac{3(a-c+\varepsilon)}{4} \text { and } Q_{2}=\widetilde{Q}_{F}=\frac{3(a-c+\varepsilon)}{4} \text { if } \varepsilon<\frac{2(a-c)}{9} \\
& =Q_{N}=\frac{3(a-c)+2 \varepsilon}{4} \quad=\widetilde{Q}_{F}=\frac{3(a-c+\varepsilon)}{4} \quad \text { if } \frac{2(a-c)}{9} \leq \varepsilon<\frac{a-c}{2} \\
& =Q_{N}=a-c \quad=\widetilde{Q}_{N}=\frac{3(a-c)+\varepsilon}{4} \text { if } \frac{a-c}{2} \leq \varepsilon<a-c \\
& =Q_{N}=\frac{a-c+\varepsilon}{2} \quad=\widetilde{Q}_{N}=\frac{a-c+\varepsilon}{2} \quad \text { if } \varepsilon \geq a-c
\end{aligned}
$$

and,

$$
\begin{aligned}
\Pi_{1} & =\Pi_{F}=\frac{1}{16}\left[3(\mathrm{a}-\mathrm{c})^{2}+3 \varepsilon^{2}+6 \varepsilon(\mathrm{a}-\mathrm{c})\right] & & \text { if } \varepsilon<\frac{2(a-c)}{9} \\
& =\Pi_{N}=\frac{1}{16}\left[3(\mathrm{a}-\mathrm{c})^{2}+12 \varepsilon^{2}+4 \varepsilon(\mathrm{a}-\mathrm{c})\right] & & \text { if } \frac{2(a-c)}{9} \leq \varepsilon<\frac{a-c}{2} \\
& =\Pi_{N}=\varepsilon(a-c) & & \text { if } \frac{a-c}{2} \leq \varepsilon<a-c \\
& =\Pi_{N}=\frac{(a-c+\varepsilon)^{2}}{4} & & \text { if } \varepsilon \geq a-c
\end{aligned}
$$

and 


$$
\begin{aligned}
\Pi_{2} & =\widetilde{\Pi}_{F}=\frac{1}{16}\left[3(\mathrm{a}-\mathrm{c})^{2}+3 \varepsilon^{2}+6 \varepsilon(\mathrm{a}-\mathrm{c})\right] & & \text { if } \varepsilon<\frac{2(a-c)}{9} \\
& =\widetilde{\Pi}_{F}=\frac{1}{16}\left[3(\mathrm{a}-\mathrm{c})^{2}+3 \varepsilon^{2}+6 \varepsilon(\mathrm{a}-\mathrm{c})\right] & & \text { if } \frac{2(a-c)}{9} \leq \varepsilon<\frac{a-c}{2} \\
& =\widetilde{\Pi}_{N}=\frac{1}{16}\left[3(\mathrm{a}-\mathrm{c})^{2}+11 \varepsilon^{2}+2 \varepsilon(\mathrm{a}-\mathrm{c})\right] & & \text { if } \frac{a-c}{2} \leq \varepsilon<a-c \\
& =\widetilde{\Pi}_{N}=\frac{(a-c+\varepsilon)^{2}}{4} & & \text { if } \varepsilon \geq a-c
\end{aligned}
$$

Now, we can show that

$$
\begin{aligned}
& Q_{1}<Q_{2} \text { if } \varepsilon \in\left[\frac{2(a-c)}{9}, \frac{a-c}{2}\right) \\
& Q_{1} \geq Q_{2} \text { if } \varepsilon \notin\left[\frac{2(a-c)}{9}, \frac{a-c}{2}\right)
\end{aligned}
$$

but,

$$
\Pi_{1} \geq \Pi_{2} \forall \varepsilon
$$

Comparing overall welfare we have,

$$
\begin{aligned}
& W_{1}<W_{2} \quad \text { if } \varepsilon \in\left[\frac{2(a-c)}{9}, \frac{a-c}{2}\right) \\
& W_{1} \geq W_{2} \text { if } \varepsilon \notin\left[\frac{2(a-c)}{9}, \frac{a-c}{2}\right)
\end{aligned}
$$

Hence we can write the following proposition.

Proposition 5: Assume that only fee licensing is allowed. (a) Industry profit is always larger if leader is the innovator. Leader's Innovation is also more valuable to the consumers as well as to the society except when $\varepsilon \notin[2(a-c) / 9,(a-c) / 2)$, in which case follower's innovation is more valuable.

Comparing results of Propositions 4 and 5 it is now quite clear that welfare implication of technology transfer depends, to a large extent, on the nature of the contract available to the innovator and the type of the firm that successfully comes up with the innovation. It also depends on the size of the innovation.

\subsection{Welfare comparison: fee versus royalty licensing}

Given the size of the innovation, which firm will come out with the innovation may be thought to be determined by a bidding game (see the next section). In such a situation the government may decide which licensing contract is to be allowed. In this section we examine which contract will generate larger welfare to different groups. Basically it is a welfare comparison between sections 2.2.1 and 2.2.2 and between 2.3.1 and 2.3.2. 


\subsubsection{Leader is the innovator}

Suppose that leader is the innovator. Now, when only royalty contract is allowed (or, in fact we may assume that both contracts are allowed), the aggregate outputs and profits are given by equations (50) and (51) respectively, that is,

$$
\begin{array}{rlrlrl}
Q_{1}(R) & =\frac{3(a-c)+2 \varepsilon}{4} \text { and } \Pi_{1}(R) & =\frac{1}{16}\left[3(a-c)^{2}+4 \varepsilon^{2}+8 \varepsilon(a-c)\right. & \text { if } \varepsilon<\frac{a-c}{2} \\
& =a-c & & \varepsilon(a-c) & \text { if } \frac{a-c}{2} \leq \varepsilon<a-c \\
& =\frac{a-c+\varepsilon}{2} & & & & \\
& & & \text { if } \varepsilon \geq a-c &
\end{array}
$$

When only fee contract is allowed, the corresponding aggregate outputs and profits are the expressions in (56) and (57),

$$
\begin{aligned}
& Q_{1}(F)=\frac{3(a-c+\varepsilon)}{4} \text { and } \Pi_{1}(F)=\frac{1}{16}\left[3(a-c)^{2}+3 \varepsilon^{2}+6 \varepsilon(a-c)\right] \quad \text { if } \varepsilon<\frac{2(a-c)}{9} \\
& =\frac{3(a-c)+2 \varepsilon}{4} \quad=\frac{1}{16}\left[3(a-c)^{2}+12 \varepsilon^{2}+4 \varepsilon(a-c)\right] \text { if } \frac{2(a-c)}{9} \leq \varepsilon<\frac{a-c}{2} \\
& =a-c \quad=\varepsilon(a-c) \quad \text { if } \frac{a-c}{2} \leq \varepsilon<a-c \\
& =\frac{a-c+\varepsilon}{2} \quad=\frac{(a-c+\varepsilon)^{2}}{4} \quad \text { if } \varepsilon \geq a-c
\end{aligned}
$$

Comparing industry outputs and profits in the above two situations, we shall get

$$
\begin{aligned}
& Q_{1}(R)<Q_{1}(\mathrm{~F}) \text { and } \Pi_{1}(R)>\Pi_{1}(\mathrm{~F}) \quad \text { if } \varepsilon<\frac{2(a-c)}{9} \\
& Q_{1}(R)=Q_{1}(\mathrm{~F}) \text { and } \Pi_{1}(R)>\Pi_{1}(\mathrm{~F}) \quad \text { if } \frac{2(a-c)}{9} \leq \varepsilon<\frac{a-c}{2} \\
& Q_{1}(R)=Q_{1}(\mathrm{~F}) \text { and } \Pi_{1}(R)=\Pi_{1}(\mathrm{~F}) \quad \text { if } \varepsilon \geq \frac{a-c}{2}
\end{aligned}
$$

The overall welfare comparisons will yield

$$
\begin{aligned}
& W_{1}(R)<W_{1}(\mathrm{~F}) \quad \text { if } \varepsilon<\frac{2(a-c)}{9} \\
& W_{1}(R)>W_{1}(\mathrm{~F}) \quad \text { if } \frac{2(a-c)}{9} \leq \varepsilon<\frac{a-c}{2} \\
& W_{1}(R)=W_{1}(\mathrm{~F}) \quad \text { if } \varepsilon \geq \frac{a-c}{2}
\end{aligned}
$$

\subsubsection{Follower is the innovator}

When only royalty contract is allowed, industry outputs and profits are given by (52) and (53), respectively, 


$$
\begin{aligned}
Q_{2}(R) & =\frac{3(a-c)+\varepsilon}{4} \text { and } & \Pi_{2}(R) & =\frac{1}{16}\left[3(a-c)^{2}+3 \varepsilon^{2}+10 \varepsilon(a-c)\right] & \text { if } \varepsilon<a-c \\
& =\frac{a-c+\varepsilon}{2} & & =\frac{(a-c+\varepsilon)^{2}}{4} & \text { if } \varepsilon \geq a-c
\end{aligned}
$$

and when only fee contract is allowed, the corresponding output and profit expressions are given in (56) and (58),

$$
\begin{aligned}
& Q_{2}(F)=\frac{3(a-c+\varepsilon)}{4} \text { and } \Pi_{2}(\mathrm{~F})=\frac{1}{16}\left[3(a-c)^{2}+3 \varepsilon^{2}+6 \varepsilon(a-c)\right] \quad \text { if } \varepsilon<\frac{a-c}{2} \\
& =\frac{3(a-c)+\varepsilon}{4} \quad=\frac{1}{16}\left[3(a-c)^{2}+11 \varepsilon^{2}+2 \varepsilon(a-c)\right] \text { if } \frac{a-c}{2} \leq \varepsilon<a-c \\
& =\frac{a-c+\varepsilon}{2} \quad=\frac{(a-c+\varepsilon)^{2}}{4} \quad \text { if } \varepsilon \geq a-c
\end{aligned}
$$

Then output and profit comparisons give

$$
\begin{array}{lll}
Q_{2}(R)<Q_{2}(\mathrm{~F}) \text { and } \Pi_{2}(R)>\Pi_{2}(\mathrm{~F}) \text { if } \varepsilon<\frac{a-c}{2} \\
Q_{2}(R)<Q_{2}(\mathrm{~F}) \text { and } \Pi_{2}(R)>\Pi_{2}(\mathrm{~F}) \text { if } \frac{a-c}{2} \leq \varepsilon<a-c \\
Q_{2}(R)=Q_{2}(\mathrm{~F}) \text { and } \Pi_{2}(R)=\Pi_{2}(\mathrm{~F}) \text { if } \varepsilon \geq a-c
\end{array}
$$

The overall welfare comparison is,

$$
\begin{array}{ll}
W_{2}(R)<W_{2}(\mathrm{~F}) & \text { if } \varepsilon<\frac{a-c}{2} \\
W_{2}(R)>W_{2}(\mathrm{~F}) & \text { if } \frac{a-c}{2} \leq \varepsilon<a-c \\
W_{2}(R)=W_{2}(\mathrm{~F}) & \text { if } \varepsilon \geq a-c
\end{array}
$$

Comparing (61) and (63), and (62) and (64) we write the following proposition. ${ }^{8}$

\section{Proposition 6:}

(a) No matter which firm innovates, if the innovation is non-drastic, consumers prefer fee contract whereas producers prefer royalty contract; if the innovation is drastic, they are indifferent between these contracts.

(b) Irrespective of the question of which firm innovates, from the perspective of social welfare fee contract is preferred if the innovation size is quite small (i.e., $\varepsilon<2(a-c) / 9)$, and royalty contract is preferred if the innovation size relatively large (i.e., $\varepsilon \geq(a-c) / 2)$. For the intermediate size of the innovation (i.e., $2(a-c) / 9 \leq \varepsilon<(a-c) / 2)$, fee licensing will generate a larger welfare if follower is

\footnotetext{
${ }^{8}$ Note that in this case there is a scenario where consumers prefer fee licensing whereas the overall welfare is larger under royalty licensing.
} 
the innovator and royalty licensing will generate a larger welfare if leader is the innovator.

\section{Innovative incentives}

In our previous analysis we have assumed that which firm holds the patent of a superior technology is exogenous in the model. In practice it may be determined endogenously. Which firm is to be allowed to do R\&D may also be a policy question. Sometimes some firms are, technically or financially, more competent to do R\&D than others. In the last section we have shown that whether leader's innovation or follower's innovation is (socially) more valuable depends on the nature of the licensing contract available to the firm, given the size of the innovation. So as a policy the government may encourage (say, by subsidizing the firm's R\&D investment) or discourage some firms' R\&D activities. It is again possible that the producing firms are not capable of doing research, but given the value of research to them they compete for the output of a research firm. This means which firm will come out with the innovation is determined by a bidding game. The government may be very selective to design its licensing policy and may directly regulate the nature of the licensing contract.

Let us denote by $\Pi(1)$ and $\Pi(2)$ the ex ante payoffs of firm 1 and firm 2 when firm 1 (leader) is the innovator; similarly, $\widetilde{\Pi}(1)$ and $\widetilde{\Pi}(2)$ denote their payoffs when firm 2 (follower) is the innovator. Then innovation incentives of firm $i, \Phi_{i}(\varepsilon)$, is defined as follows:

$$
\Phi_{1}(\varepsilon)=\Pi(1)-\widetilde{\Pi}(1) \text { and } \Phi_{2}(\varepsilon)=\widetilde{\Pi}(2)-\Pi(2)
$$

that is, innovation incentives of a firm is its payoff when it succeeds to innovate but the rival fails minus its payoff when the rival succeeds but it fails. In other words, this is the maximum amount that a firm can spend on wining the patent of an innovation of size $\varepsilon$. We further note that when the innovation is drastic (i.e., $\varepsilon \geq a-c$ ), the patent holder becomes pure monopoly, and so it has no further any incentive to transfer its technology even if it has that option (see section 2). So it gets a monopoly payoff, $\pi^{m}=(a-c+\varepsilon)^{2} / 4$, while the rival has zero payoff. Hence $\Phi_{i}(\varepsilon)=\pi^{m} \forall i$, that is, both leader and follower have identical incentive to win the patent of a drastic innovation. In the following analysis, therefore, we restrict to the assumption that the innovation is non-drastic (i.e., $\varepsilon<a-c$ ).

\subsection{Technology transfer not allowed}

In this case the post-innovation payoffs are given by (8) when firm 1 is the innovator, and by (26) when firm 2 is the innovator. Therefore,

$$
\begin{aligned}
\Phi_{1}(\varepsilon)=\Pi(1)-\widetilde{\Pi}(1)=\pi_{1}^{N}-\tilde{\pi}_{1}^{N} & =\frac{(a-c+2 \varepsilon)^{2}}{8}-\frac{(a-c-\varepsilon)^{2}}{8} \quad \text { if } \varepsilon<\frac{a-c}{2} \\
& =\varepsilon(a-c)-\frac{(a-c-\varepsilon)^{2}}{8} \quad \text { if } \frac{a-c}{2} \leq \varepsilon<a-c
\end{aligned}
$$


and

$$
\begin{aligned}
\Phi_{2}(\varepsilon)=\widetilde{\Pi}(2)-\Pi(2)=\tilde{\pi}_{2}^{N}-\pi_{2}^{N} & =\frac{(a-c+3 \varepsilon)^{2}}{16}-\frac{(a-c-2 \varepsilon)^{2}}{16} \\
& =\frac{(a-c+3 \varepsilon)^{2}}{16}-0 \quad \text { if } \varepsilon<\frac{a-c}{2} \\
& \text { if } \frac{a-c}{2} \leq \varepsilon<a-c
\end{aligned}
$$

Then it can be shown that

$$
\Phi_{1}(\varepsilon)>\Phi_{2}(\varepsilon) \forall \varepsilon<a-c
$$

that is, leader has a larger incentive in this case.

\subsection{Only fee licensing contract allowed}

Assume that only fee licensing is allowed in the post-innovation situation. Then if firm 1 is the innovator, technology transfer occurs iff $\varepsilon<2(a-c) / 9$, and if firm 2 is the innovator, technology licensing occurs iff $\varepsilon<(a-c) / 2$. In all other cases no transfer will occur. Hence the innovation incentives are defined as follows:

$$
\begin{aligned}
\Phi_{1}(\varepsilon) & =\Pi_{1}^{F}-\left(\tilde{\pi}_{1}^{F}-\widetilde{F}\right)=\left[\frac{3(a-c+\varepsilon)^{2}}{16}-\frac{(a-c-2 \varepsilon)^{2}}{16}\right]-\frac{(a-c-\varepsilon)^{2}}{16} & \text { if } \varepsilon<\frac{2(a-c)}{9} \\
& =\pi_{1}^{N}-\tilde{\pi}_{1}^{N}=\frac{(a-c+2 \varepsilon)^{2}}{8}-\frac{(a-c-\varepsilon)^{2}}{8} & \text { if } \frac{2(a-c)}{9} \leq \varepsilon<\frac{a-c}{2} \\
& =\pi_{1}^{N}-\tilde{\pi}_{1}^{N}=\varepsilon(a-c)-\frac{(a-c-\varepsilon)^{2}}{8} & \text { if } \frac{a-c}{2} \leq \varepsilon<a-c
\end{aligned}
$$

and

$$
\begin{aligned}
\Phi_{2}(\varepsilon) & =\widetilde{\Pi}_{2}^{F}-\left(\pi_{2}^{F}-F\right)=\left[\frac{3(a-c+\varepsilon)^{2}}{16}-\frac{(a-c-\varepsilon)^{2}}{8}\right]-\frac{(a-c-2 \varepsilon)^{2}}{16} \text { if } \varepsilon<\frac{2(a-c)}{9} \\
& =\widetilde{\Pi}_{2}^{F}-\left(\pi_{2}^{F}-\mathrm{F}\right)=\left[\frac{3(a-c+\varepsilon)^{2}}{16}-\frac{(a-c-\varepsilon)^{2}}{8}\right]-\frac{(a-c-2 \varepsilon)^{2}}{16} \text { if } \frac{2(a-c)}{9} \leq \varepsilon<\frac{a-c}{2} \\
& =\tilde{\pi}_{2}^{N}-\pi_{2}^{N}=\frac{(a-c+3 \varepsilon)^{2}}{16}-0 \quad \text { if } \frac{a-c}{2} \leq \varepsilon<a-c
\end{aligned}
$$

We can then check that

$$
\begin{aligned}
& \Phi_{1}(\varepsilon)=\Phi_{2}(\varepsilon) \text { if } \varepsilon<2(a-c) / 9 \\
& \Phi_{1}(\varepsilon)>\Phi_{2}(\varepsilon) \text { if } 2(a-c) / 9 \leq \varepsilon<a-c
\end{aligned}
$$

Thus, if only fee licensing is allowed, leader has larger incentives to hold the patent of the innovation. 


\subsection{Both licensing contracts allowed}

Now assume that both (fee and royalty) licensing contracts are allowed. We have already noted that fee licensing will never figure in equilibrium in this case. Then if firm 1 holds the patent, royalty licensing occurs iff $\varepsilon<(a-c) / 2$, and if firm 2 is the innovator, technology licensing (with royalty contract) occurs iff $\varepsilon<a-c$. In all other cases no transfer is the outcome. Then their innovation incentives are as follows:

$$
\begin{aligned}
\Phi_{1}(\varepsilon) & =\Pi_{1}^{R}-\tilde{\pi}_{1}^{R}=\left[\frac{(a-c+2 \varepsilon)^{2}}{8}+\varepsilon \frac{(a-c-2 \varepsilon)}{4}\right]-\frac{(a-c-\varepsilon)^{2}}{8} & \text { if } \varepsilon<\frac{a-c}{2} \\
& =\pi_{1}^{N}-\tilde{\pi}_{1}^{R}=\varepsilon(a-c)-\frac{(a-c-\varepsilon)^{2}}{8} & \text { if } \frac{a-c}{2} \leq \varepsilon<a-c
\end{aligned}
$$

Similarly,

$$
\begin{aligned}
\Phi_{2}(\varepsilon) & =\widetilde{\Pi}_{2}^{R}-\pi_{2}^{R}=\left[\frac{(a-c+3 \varepsilon)^{2}}{16}+\varepsilon \frac{(a-c-\varepsilon)}{2}\right]-\frac{(a-c-2 \varepsilon)^{2}}{16} \text { if } \varepsilon<\frac{a-c}{2} \\
& =\widetilde{\Pi}_{2}^{R}-\pi_{2}^{N}=\left[\frac{(a-c+3 \varepsilon)^{2}}{16}+\varepsilon \frac{(a-c-\varepsilon)}{2}\right]-0 \quad \text { if } \frac{a-c}{2} \leq \varepsilon<a-c
\end{aligned}
$$

By comparing,

$$
\Phi_{1}(\varepsilon)<\Phi_{2}(\varepsilon) \forall \varepsilon<a-c
$$

Hence if both contracts are allowed (or only royalty contract is allowed), follower has larger incentives to innovate.

Now, based on the analysis of this section we have the following proposition.

Proposition 7: If technology transfer is not allowed, or is allowed only with a fixed fee contract, then in a leadership structure, leader has larger incentives to innovate, but if royalty licensing is also allowed, follower has larger incentives.

Intuition of the result is the following. The post-transfer industry profit under fee licensing (if transfer occurs) is the same irrespective of the firm holds the patent. But there are situations (as defined in terms of the size of the innovation) when transfer can take place only if follower is the innovator. In such a situation, therefore, the loss of payoff to the leader is much larger if it fails to innovate, and hence it has larger incentives for innovation. On the other hand, when royalty contract is also available, follower has larger innovative incentives because due to its move disadvantage its loss of profit when it fails to innovate is much larger compared to that of the leader when leader is unsuccessful in innovation.

\section{Optimal policy choice}

In view of our analysis made in the last two sections we can now suggest more concretely the policy choices of the government. Throughout the paper we assume that the size of the innovation is exogenous. Then given the size of the innovation, in Section 3 we have

discussed whose innovation, whether leader's or follower's, is socially more valuable 
(see Propositions 4 and 5). We have also discussed which licensing contract, whether fee licensing or royalty licensing, generates larger welfare (see Proposition 6). Finally, in Section 4 we have examined which firm has larger incentives to win the patent competition (see Proposition 7). This analysis shows that the government of a country can, by its choice of a policy regarding which contract may be allowed in a given situation, influence the innovation decision of a firm, and thus it can make sure that the socially desired firm comes up with the innovation. This analysis, therefore, assumes that the government can effectively implement its licensing policy (viz., the contract which is to be allowed and which not), but it cannot directly force a firm to do R\&D.

From Proposition 7 we know that if the government restricts the choice of the firms to fee licensing only, then in general leader has larger incentive to innovate. On the other hand, if the firms are allowed to write only royalty licensing contract (or alternatively, if the firms are allowed to choose either of these contracts, in which case both leader and follower prefer royalty contract), follower has larger incentive to innovate. ${ }^{9}$ Then given that only fee licensing is allowed, so that leader comes out with the innovation, the corresponding industry output and profit will be respectively $Q_{1}(F)$ and $\Pi_{1}(F)$, as given in section 3.3.1. Similarly, if both fee and royalty contracts are allowed, so that follower comes up with innovation, the industry output and profit expressions are $Q_{2}(R)$ and $\Pi_{2}(R)$, as given in section 3.3.2.

Let $W_{F}^{*}$ and $W_{R}^{*}$ denote respectively the social welfare under the policy that only fee licensing is allowed and both royalty and fee licensing options are allowed. Hence,

$$
W_{F}^{*}=\frac{1}{2}\left[Q_{1}(F)\right]^{2}+\Pi_{1}(F) \text { and } W_{R}^{*}=\frac{1}{2}\left[Q_{2}(R)\right]^{2}+\Pi_{2}(R) .
$$

Then comparing welfare levels under these two policy regimes we shall have,

$$
\begin{array}{ll}
W_{F}^{*}>W_{R}^{*} & \text { if } \varepsilon<2(a-c) / 9 \\
W_{F}^{*}<W_{R}^{*} & \text { if } 2(a-c) / 9 \leq \varepsilon<2(a-c) / 7 \\
W_{F}^{*}>W_{R}^{*} & \text { if } 2(a-c) / 7 \leq \varepsilon<(a-c) \\
W_{F}^{*}=W_{R}^{*} & \text { if } \varepsilon \geq a-c
\end{array}
$$

This leads to the following conclusion.

Proposition 8: The policy allowing both royalty and fee licensing is optimal if and only if $\varepsilon \in[2(a-c) / 9,2(a-c) / 7]$; in all other cases, allowing only fee licensing is the optimal policy.

This may be explained as follows. If licensing occurs under royalty contract, consumers have nothing to gain compared to no licensing situation, whereas if fee licensing occurs, consumers gain by means of larger outputs and lower product price. Generally, this gain

\footnotetext{
${ }^{9}$ In fact, if only fee licensing is allowed and $\varepsilon<2(a-c) / 9$, both leader and follower have same incentives (see (65)), and also welfare is same whoever innovates.
} 
outweighs the loss of profits (if any), and hence fee licensing in general should be encouraged. But there are situations when fee licensing is not profitable whereas transfer will occur if royalty contract is available. Allowing royalty contract in such a situation means consumers are not losing anything under technology licensing but producers' profits as a whole may go up, and hence royalty contract is to be favored under this parametric situation.

\section{Conclusion}

In this paper we have considered a two-firm leader-follower structure with one firm, either leader or follower, holding a patent of an innovation. Clearly, leadership structure is retained if the innovation is non-drastic. We have then studied the possibility of technology transfer between the firms in the situation where only fee licensing is available or both fee licensing and royalty licensing are available. We have shown that if the innovation is drastic, technology transfer will never take place. However, when the innovation is non-drastic, from the perspective of the patent holder royalty contract strictly dominates fee contract if licensing is at all profitable (Proposition 1 and 2). Thus it does not matter whether only royalty contract is available or both contracts are available. There are, however, situations when royalty contract may not be available and hence only fee contract is available. For instance, royalty contract cannot be written if patent protection is imperfect and imitation of the transferred technology is easy.

Then we have demonstrated that welfare implication of technology transfer depends on who holds the patent of the superior technology and which licensing contract is available to the firms. It also depends on the size of the innovation assumed exogenous in the paper. From the perspective of aggregate industrial profit, royalty contract is preferred. This, therefore, calls for a stricter enforcement of patent rules. On the other hand, consumers' welfare is larger under fee licensing. Which contract is preferred from the viewpoint of the society as a whole, however, depends on the size of the innovation. For example, fee licensing is preferred if the innovation size is quite small and royalty contract is preferred if it is relatively larger. For the middle size innovation fee licensing gives larger welfare if follower is the innovator and royalty generates larger welfare if leader is the innovator (Proposition 6)

We have also examined whose innovation, whether leader's, or follower's, is considered to be more valuable. Our results are the following. If only fee contract is available, industry profit is always larger if leader is the innovator; leader's innovation is also considered to be more valuable to the consumers as well as to the society except when innovation is of middle level (Proposition 5). On the other hand, if royalty contract is also available, follower's innovation is considered more valuable to the producers, but leader's innovation generates larger consumers' as well as social welfare (Proposition 4).

We have then examined which firm has larger incentives to innovate. We have assumed that the winner of the patent race is determined by a bidding game. Which contract is available to the innovator is important in this context. In particular, we have shown that if only fee licensing is available, leader will have higher incentives to innovate, whereas if 
royalty contract is also available, the follower has strictly larger incentives when the innovation is non-drastic. In case of drastic innovation both firms have identical incentives (Proposition 7). This calls for a policy choice by the government as to what should be the socially optimal licensing contract. When objective of the government is to maximize social welfare, the government should restrict the choice of the licensing contract to fee contract alone except for a small interval of the size of the innovation Proposition 8). Thus by its choice of a particular policy the government can induce the desired firm to innovate the technology.

So far the limitation of the paper is concerned, we have assumed that the demand function for the product is linear. However, it is unlikely that any of our results will undergo a qualitative change if the demand function is non-linear. Finally, we have assumed that the size of the innovation is exogenous. Hence one immediate extension of the present work should be to endogenize the choice of the innovation size. Then it will be interesting to examine which licensing contract will generate larger welfare to the consumers and producers separately and as a whole. 


\section{References}

Alam, G., 1985, "India's technology policy and its influence on technology imports and technology development", Economic and Political Weekly, Special Number (November), 2073-80.

Arrow, K., 1962, "Economic welfare and the allocation of resources for innovation", in Nelson, R.R. (ed.), The Rate and Direction of Inventive Activity, Princeton University Press.

Economic and Political Weekly, Special Number (November), 1985

Kabiraj, T. and S. Marjit, 1992, "To transfer or not to transfer the best technology under threat of entry - the case of price competition", in B. Dutta, D. Mukherjee, T. Parthsarathy, T.E.S. Raghavan, D. Roy and S. Tijs (eds.) Game Theory and Economic Applications, Springer-Verlag.

Kabiraj, T. and S. Marjit, 1993, "International technology transfer under potential threat of entry: a Cournot-Nash framework", Journal of Development Economics 42, 75-88.

Kamien, M., 1992, "Patent licensing", in Aumann, R.J. and S. Hart, (eds.), Handbook Of Game Theory, Ch. 11.

Kamien, M. and Y. Tauman, 1984, "The private value of a patent: a game theoretic analysis", Journal of Economics (Supplement) 4, 93-118.

Kamien, M. and Y. Tauman, 1986, "Fees versus royalties and the private value of a patent", Quarterly Journal of Economics 101, 471-491.

Katz, M. and C. Shapiro, 1985, "On the licensing of innovation", Rand Journal of Economics 16, 504-519.

Marjit, S., 1990, "On a non-cooperative theory of technology transfer", Economics Letters 33, 293-298.

Muto, S., 1993, "On licensing policies in Bertrand competition”, Games and Economic Behavior 5, 257-267.

Rockett, K., 1990, "The quality of licensed technology", International Journal of Industrial Organization 8, 559-574.

Rostoker, M., 1984, A survey of corporate licensing, IDEA 24, 59-92.

Shapiro, C., 1985, "Patent licensing and R\&D rivalry", American Economic Review 75, 139-152. 
Singh, N., 1992, "Multinationals, technology and government policy", in Basu, K. and P. Nayak (eds.), Development Policy and Economic Theory, Oxford University Press, Delhi.

Wang, X.H., 1998, "Fee versus royalty licensing in a Cournot duopoly model", Economics Letters 60, 55-62. 